\title{
IMPLEMENTATION of AJAX and JSON to IMPROVE WEB APPLICATION PERFORMANCE
}

\author{
Muhammad Zakki Abdillah \\ Program Studi Teknik Informatika \\ Fakultas Teknologi Informasi dan Komunikasi, Universitas Semarang \\ Semarang, Indonesia \\ zakki@usm.ac.id
}

\begin{abstract}
AJAX is not a language programming, but a technic that possible to create interactive web application. With AJAX, web application can interaction with server in back screen, so not influence web page overall. The method of displaying the result request from user and viewed in to system without must reload page overall. AJAX representation performed with creating programming in the system. This research provides a bridge between the user request and server response, so as to ease the burden of the server as seen from the server memory in unused.

The result from this research is system can provides a faster display from the previous system. Testing system based on a rapid access on each menu. The result comparison between the old system and the new system is 43,8 versus 78,4 and server memory used is $2.112 \mathrm{MB}$ versus $2.095 \mathrm{MB}$ with 8 users. This comparison provides information that system with AJAX better to be used on building a system.
\end{abstract}

Keywords - AJAX; Web Application ; JSON;

\section{PENDAHULUAN}

Asynchronous Javascript And XML (AJAX) merupakan perkembangan dari Dynamic HTML (DHTML) yang menggunakan XMLHttpRequest dan Javascript yang dihubungkan secara asynchronous. Tujuan AJAX adalah meringankan beban server ketika mendapatkan request dari client, sehingga mesin AJAX memprosesnya sebelum masuk ke dalam server.[1]. Metode AJAX sudah di implementasikan ke dalam aplikasi web yang sudah populer, misalnya : Google Suggest, google docs, gmail, facebook, yahoo, dll

Data yang diambil dari AJAX adalah XML, yang merupakan kata terakhir dari AJAX. XML menguraikan data dengan cara yang standar dan pengguna dapat membuat format tersebut. Salah satu kelebihan AJAX adalah penggabungan dengan JSON (JavaScript Object Notation).[2]. XML yang merupakan format database yang akan di tampilkan akan di konversi ke dalam JSON. Penguraian XML ke JSON tersebut ternyata lebih efektif dibandingkan dengan hanya menggunakan XML saja dalam menyediakan data.

Penelitian ini bertujuan untuk memberikan alternatif lain dalam membuat aplikasi web yang interaktif dan responsif dengan menggunakan AJAX dan JSON. Dengan metode AJAX mampu memberikan tampilan yang lebih baik dan JSON dapat meningkatkan pemrosesan data dan pendelegasian data ke sistem yang lain. Hal ini dapat menjadi bahan evaluasi bagi pejabat Universitas untuk mempertimbangkan adanya perubahan sistem yang sudah ada.

Data yang di buat untuk memproses data adalah data dari Sistem Informasi Akademik, lebih khususnya pada bagian Kartu Rencana Studi (KRS) mahasiswa. Dari data KRS in akan membandingkan sistem yang menggunakan AJAX dan sistem yang tidak menggunakan AJAX. Perbandingan kedua sistem ini di lihat dari memori server yang terpakai, dan kecepatan akses, dengan mengambil jumlah pengguna yang sama, dan bandwith yang sama. Dari data tersebut, nantinya akan bisa dibandingkan sistem mana yang lebih cepat, responsif dan bagus untuk di kembangkan.

\section{KERANGKA TEORI}

\section{A. Asynchronous Javascript And XML (AJAX)}

Model aplikasi web dengan AJAX berkomunikasi secara langsung dengan server melalui objek javascript yaitu XMLHttpRequest. Objek XMLHttpRequest merupakan suatu jembatan antara server dengan client. Halaman yang mendapatkan request, dan merespon dari server tanpa mereload halaman secara keseluruhan. User tetap dengan halaman yang sama, bahkan user tidak tahu ada data yang dikirim dan diterima dari server, karena javascript melakukan transaksi data dibalik layar.[3]

Model web menggunakan AJAX mengirimkan permintaan (request) memakai proses asynchronous, proses pengiriman tersebut berarti kode javascript tidak menunggu server untuk merespon, sehingga pengguna dapat menggunakan aplikasi.

Kode javascript mendapatkan data, melakukan perhitungan, dan mengirim permintaan lain tanpa- melibatkan pengguna. Proses ini adalah kekuatan XMLHttpRequest yang dilakukan secara bersamaan dengan server yang diinginkan, tanpa pernah tahu pengguna tentang apa yang sebenarnya terjadi. Hasil dari proses tersebut adalah, dinamis responsif, pengalaman yang sangat interaktif seperti aplikasi desktop, tetapi dengan semua kekuatan internet di belakangnya.

\section{B. JavaScript Object Notation (JSON)}

JSON merupakan suatu format ringkas pertukaran data pada sebuah sistem komputer, format JSON berbasis teks, sehingga property dan value-nya dapat disesuaikan dengan format teks manusia. 
JSON seperti XML (eXtensible Markup Language) karena keduanya merupakan model data semi terstruktur. JSON menggantikan XML di beberapa aplikasi karena relative lebih sederhana, ringan, dan dapat langsung memetakan ke jenis data asli dari pemrograman yang sering di pakai (misalnya javascript), tidak seperti dokumen XML yang berinteraksi melalui API seperti DOM atau SAX. [4]

\section{PEMBAHASAN}

Permasalahan sistem yang mempunyai banyak pengguna adalah kecepatan akses, sehingga pengembangan sistem lebih mendalam untuk peningkatan kecepatan akses selain juga keamanan sistem. Penelitian ini akan menjelaskan beberapa bagian untuk meningkatkan kinerja sistem, yaitu :

\section{A. Analisa Sistem Lama dan Sistem Baru}

Sistem lama yang berbasis web masih menggunakan bahasa pemrograman dan pertukaran data yang masih sederhana, yaitu hanya menggunakan PHP sebagai bahasa pemrograman dan MySQL untuk database server. Pemrosesan data hanya mengacu pada satu titik yaitu langsung ke database server, belum ada proses untuk pertukaran datanya. Sedangkan untuk tampilan depan menggunakan HTML dan CSS sebagai antar muka ke pengguna secara langsung.

Sistem baru yang akan di buat untuk memperbaiki kecepatan akses menggunakan metode AJAX dan JSON, sebenarnya bukanlah hal baru di dalam teknologi web. AJAX sebagai jembatan antara client (browser) dan server, sehingga AJAX berada tepat di tengah di antara keduanya. Cara kerja dari AJAX adalah eksploitasi dan mengambil konten, pembersihan konten, dan ekstraksi informasi. Sedangkan JSON bekerja memetakan data dari dokumen AJAX berupa XML dan mengkonversi menjadi data yang lebih ringan dan cepat untuk pemrosesan data. Dari data JSON ini di gunakan untuk pertukaran data, baik untuk internal sistem maupun untuk eksternal sistem.

Perbandingan dari sistem lama dan sistem baru dapat dijelaskan pada gambar 1, dimana sistem (web) yang tanpa menggunakan AJAX antara client berinteraksi dengan server secara langsung, yakni dari browser langsung ke web server. Sedangkan web yang menggunakan AJAX dan JSON interaksi antara client dan server di jembatani oleh AJAX, dan data hasil AJAX dikonversi ke JSON untuk mempercepat pemrosesan data karena JSON dapat mengekstraksi data menjadi lebih ringan dan cepat.
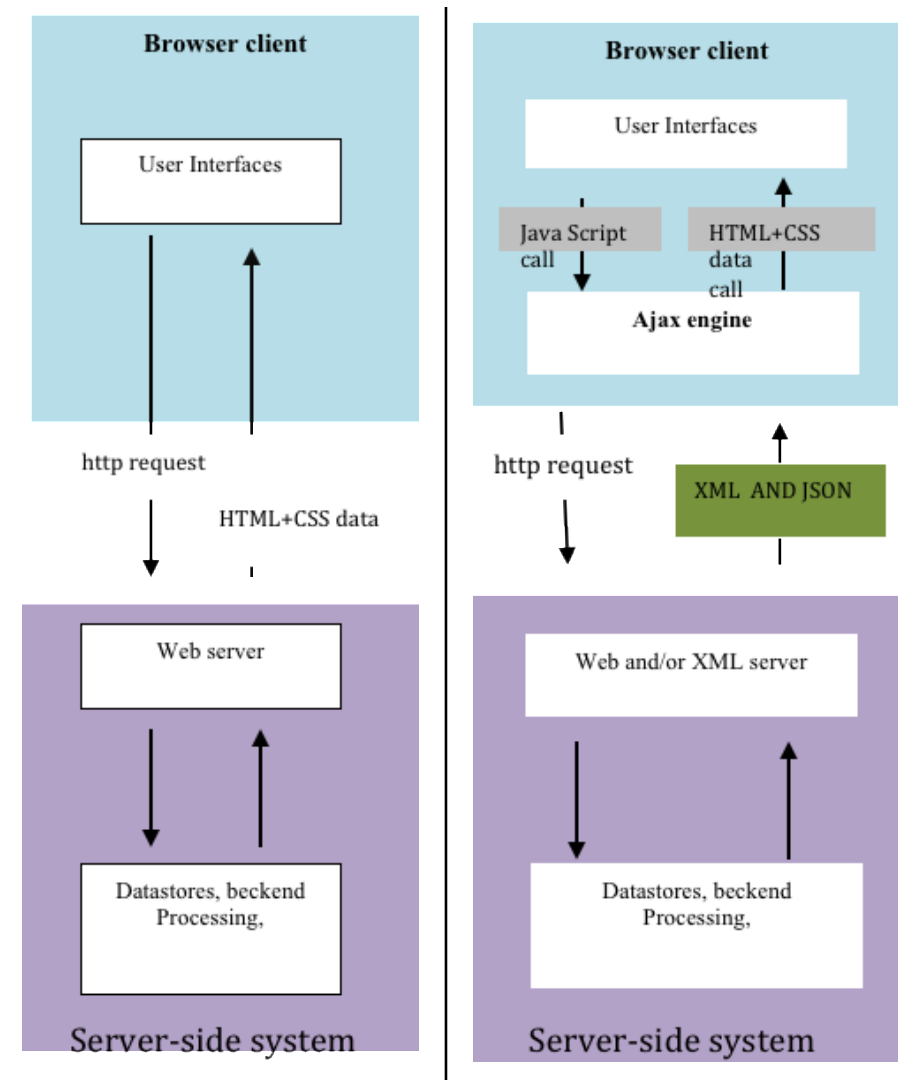

Gambar 1

Keterangan :

Model aplikasi web tradisional menggunakan html form tradisional untuk menggunakan dan mengirim database atau file ke server. Pengguna menekan tombol submit untuk mengirimkan atau mendapatkan informasi, menunggu respon dari server, dan hasilnya akan di load. Server yang selalu memberikan halaman baru ketika user menekan tombol submit, maka aplikasi web tersebut berjalan lambat dan kurang user-friendly.

Sedangkan aplikasi web yang menggunakan AJAX dan JSON ketika pengguna menekan tombol submit, proses langsung dikerjakan oleh mesin AJAX dan menegenerate data JSON untuk pemrosesan datanya. Hal ini sekilas kelihatan lebih lama karena melalui beberapa proses, tetapi pada kenyataannya semakin cepat karena proses pengembalian permintaan dari pengguna tidak langsung diambil dari server, melainkan mengambil data dari proses AJAX, sehingga lebih cepat.

\section{B. Implementasi Sistem}

Penerapan dari aplikasi web yang menggunakan AJAX menerapkan pola ketika pengguna melakukan request page (menekan suatu link atau klik tombol submit) maka AJAX melakukan proses pengambilan data dari server yang berupa dokumen JSON tanpa harus memuat semua halaman secara penuh. Hal ini terasa lebih cepat dan ringan, karena tidak perlu mengambil semua data dari keseluruhan halaman, yang kadang kali dalam sebuah halaman web memiliki berbagai 
macam jenis dokumen, baik teks, gambar, audio, video, bahkan animasi yang kadang mempunyai ukuran yang besar. Sehingga dalam langkah ini, AJAX meringkas langkah dan tidak perlu memuat semua dokumen tersebut.

Tampilan dari aplikasi web yang menggunakan AJAX seperti di bawah ini :

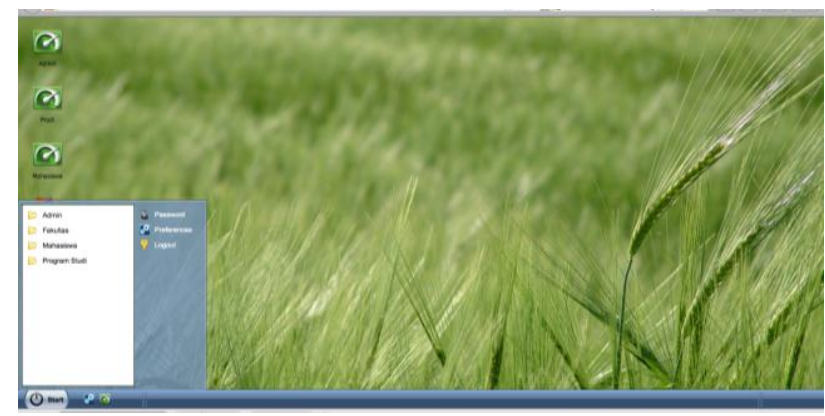

Gambar 2

Tampilan aplikasi web yang menggunakan AJAX dalam penelitian ini berbentuk seperti aplikasi desktop, lebih tepatnya seperti tampilan antar muka sistem operasi Windows. Pengguna dalam mengoperasikan aplikasi web tersebut hanya klik menu maka akan muncul jendela baru yang masih dalam satu frame aplikasi tersebut, sehingga dalam memuat halaman, AJAX tidak mengambil resource data keseluruhan, hanya data yang dibutuhkan untuk satu menu tersebut saja.

\section{Testing}

Pengujian sistem sangat penting untuk menentukan apakah sistem (aplikasi web) layak untuk di gunakan atau tidak. Berbeda dengan aplikasi desktop yang mungkin untuk mengujinya hanya sekedar apakah aplikasi tersebut sudah benar secara logika atau sudah sesuai dengan keinginan pengguna. Aplikasi web lebih beragam, karena web secara standart merupakan aplikasi client-server dan dikembangkan menjadi internet, yang pastinya mempunyai banyak pengguna.

Pengujian aplikasi web ini terdiri dari 2 sistem, yakni : sistem lama tanpa menggunakan AJAX, dan sistem baru menggunakan AJAX dan JSON yang terdapat pada gambar 3 dan 4 sebagai berikut :

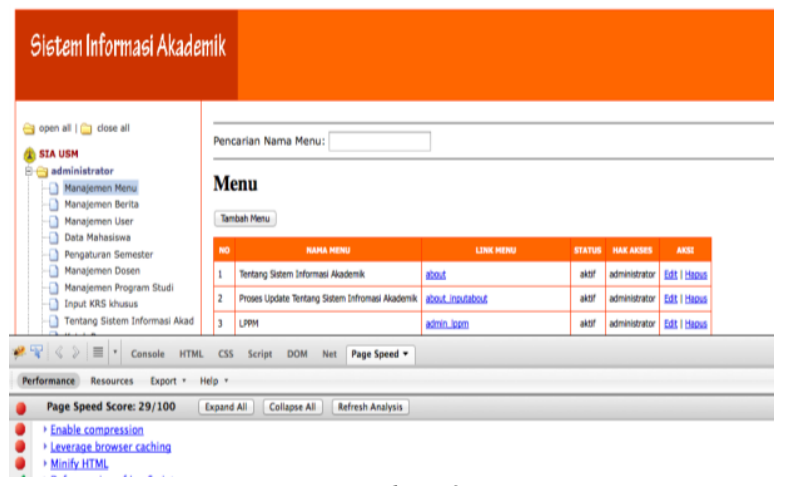

Gambar 3

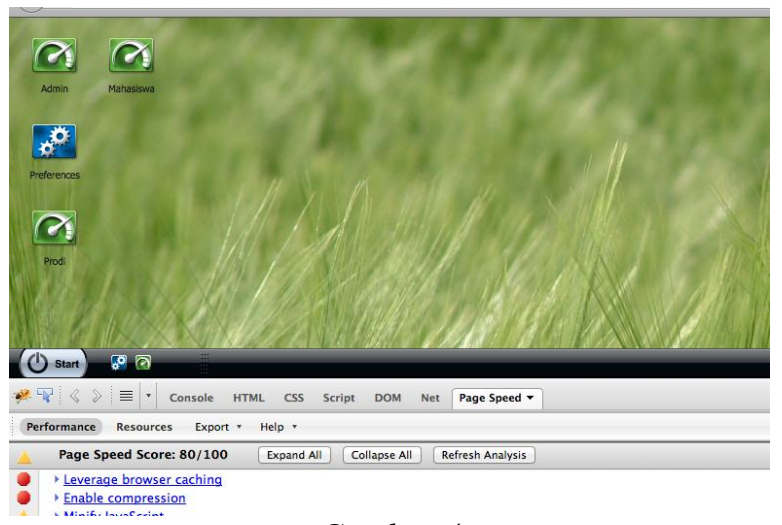

Gambar 4

Gambar 3 merupakan aplikasi web lama yang tidak menggunakan AJAX, sedangkan gambar 4 merupakan aplikasi web baru yang menggunakan AJAX dan JSON. Dilihat dari page speed (kecepatan halaman), web lama tanpa AJAX mempunyai nilai 29 dari 100, sedangkan web baru menggunakan AJAX dan JSON mempunyai nilai 80 dari 100. Dari sinilah sudah terlihat bahwa aplikasi web yang menggunakan AJAX dan JSON lebih cepat dalam hal pemrosesan data.

Pengukuran kecepatan halaman ini menggunakan page speed dari tools firebug, dimana kecepatan akses dari setiap halaman mempunyai nilai tersendiri untuk menentukan prosentase kecepatan tersebut. Nilai tersebut dari 0 sampai dengan 100 yang mengindikasikan tiap halaman berbeda nilainya. Pengujian pada gambar 3 dan 4 merupakan pengujian pada halaman menu yang menampilkan seluruh menu untuk mengelola aplikasi web tersebut.

Pengujian selanjutnya menggunakan monitoring melalui server yang diambil dari berapa memory server yang terpakai, karena ini berhubungan dengan bagaimana membuat aplikasi web yang cepat, responsive, dan mengurangi kinerja server. Pengambilan memory yang terpakai dapat digambarkan pada table dibawah ini :

\begin{tabular}{|c|c|c|c|c|c|c|}
\hline \multirow[t]{2}{*}{ NO } & \multicolumn{3}{|c|}{ SIA Lama } & \multicolumn{3}{|c|}{$\begin{array}{c}\text { SIA menggunakan } \\
\text { AJAX }\end{array}$} \\
\hline & $\mathrm{JU}$ & Speed & MT & $\mathrm{JU}$ & Speed & MT \\
\hline 1 & 6 & 28 & $2.111 \mathrm{MB}$ & 6 & 80 & $2.094 \mathrm{MB}$ \\
\hline 2 & 7 & 28 & $2.112 \mathrm{MB}$ & 7 & 80 & $2.095 \mathrm{MB}$ \\
\hline 3 & 7 & 28 & $2.114 \mathrm{MB}$ & 7 & 80 & $2.094 \mathrm{MB}$ \\
\hline 4 & 8 & 51 & $1.586 \mathrm{MB}$ & 8 & 82 & $1.577 \mathrm{MB}$ \\
\hline 5 & 7 & 53 & $1.596 \mathrm{MB}$ & 7 & 77 & $1.586 \mathrm{MB}$ \\
\hline 6 & 6 & 48 & $1.596 \mathrm{MB}$ & 6 & 74 & $1.586 \mathrm{MB}$ \\
\hline 7 & 6 & 48 & $1.613 \mathrm{MB}$ & 6 & 82 & $1.579 \mathrm{MB}$ \\
\hline 8 & 9 & 58 & $1.616 \mathrm{MB}$ & 9 & 77 & $1.578 \mathrm{MB}$ \\
\hline 9 & 6 & 48 & $1.615 \mathrm{MB}$ & 6 & 75 & $1.578 \mathrm{MB}$ \\
\hline 10 & 6 & 48 & $1.614 \mathrm{MB}$ & 6 & 77 & $1.576 \mathrm{MB}$ \\
\hline
\end{tabular}

tabel 1

Keterangan tabel :

JU : Jumlah User 
Speed : Kecepatan

MT : Memori yang terpakai

Pada tabel 1, digambarkan bahwa dengan menggunakan jumlah pengguna yang sama dalam waktu yang berbeda menghasilkan data jumlah memory yang terpakai. Dari tabel 1 terlihat bahwa memory yang terpakai untuk aplikasi web lama yang tidak menggunakan AJAX dan JSON mengambil resource memory server yang lebih banyak dibandingkan dengan aplikasi web baru yang menggunakan AJAX dan JSON. Hal ini jelas akan membuat server bekerja lebih ringan ketika menggunakan aplikasi web yang baru.

Perbandingan antara aplikasi web lama dan aplikasi web yang baru menggunakan AJAX dan JSON dapat digambarkan pada grafik 1 seperti dibawah ini :

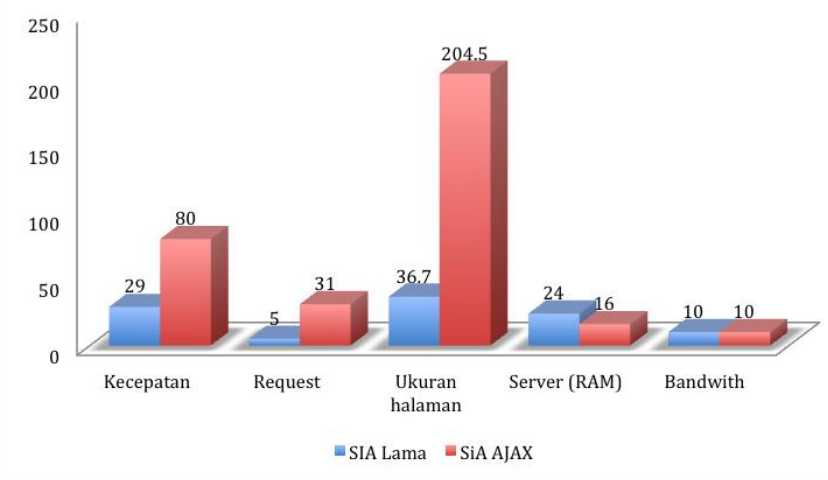

Grafik 1

Pada pengujian sistem yang terakhir membandingkan aplikasi web lama dan aplikasi web yang baru di bagi dalam 5 kategori sebagai berikut :

\section{- Kecepatan}

Dalam hal kecepatan, aplikasi web lama memperoleh nilai 29 dari 100, sedangkan aplikasi web yang baru menggunakan AJAX dan JSON memperoleh nilai 80 dari 100. Hal ini menjelaskan bahwa aplikasi web baru yang menggunakan AJAX dan JSON lebih cepat dalam hal pengaksesan data halaman web.

- Request

Jumlah request dari client (dalam hal ini pengguna) untuk aplikasi web lama lebih sedikit daripada aplikasi web baru yang menggunakan AJAX dan JSON.

\section{- Ukuran Halaman}

Ukuran halaman dalam aplikasi web sangat mempengaruhi kinerja dan kecepatan akses aplikasi web itu sendiri. Dari grafik menunjukkan bahwa aplikasi web lama lebih sedikit daripada aplikasi web baru yang menggunakan AJAX dan JSON, tetapi dalam hal kecepatan pada poin 1, aplikasi web baru lebih cepat.

- $\quad$ Server

Server merupakan aspek penting dalam aplikasi web, karena di dalam server, aplikasi dan database tersimpan. Pengaksesan semua data diambil dari server, sehingga spesifkasi server sangatlah penting. Grafik 1 menunjukkan bahwa dengan spesifikasi yang sama, tetapi jumlah memory yang berbeda menunjukkan bahwa walaupun aplikasi web yang lama lebih banyak jumlah memorynya, tetapi tidak serta merta akan membantu mengurangi kinerja server.

- Bandwith

Bandwith yang dipakai untuk pengujian kedua aplikasi web tersebut sama, karena kedua aplikasi web menggunakan bandwith yang sama yaitu $10 \mathrm{MBps}$.

\section{KESIMPULAN DAN SARAN}

Setelah mencoba untuk membandingkan antara aplikasi web lama dan aplikasi web baru yang menggunakan AJAX dan JSON, maka dapat diambil kesimpulan sebagai berikut :

- Aplikasi web memang perlu dikembangkan untuk melihat seberapa responsif untuk melakukan pemrosesan data.

- Aplikasi web baru yang menggunakan AJAX dan JSON lebih cepat dalam hal pemrosesan datanya daripada aplikasi web lama. Hal tersebut dijelaskan pada grafik 1 .

- Aplikasi web baru yang menggunakan AJAX dan JSON memang lebih besar dari sisi ukuran halamannya, karena menggunakan banyak langkah untuk pemrosesan datanya, dan menggunakan memory RAM yang lebih sedikit dibanding aplikasi web lama, tetapi hal tersebut tidak mengurangi kecepatan akses, dan dalam hal penggunaan memory RAM.

Dari kesimpulan di atas, karena keterbatasan waktu dan pembahasan, maka untuk penelitian selanjutnya dapat menjadikan saran sebagai acuan untuk memperbaiki penelitian ini. Saran untuk penelitian selanjutnya adalah :

- Pengujian aplikasi web baiknya bisa dikembangkan untuk lebih banyak komponen-komponen bahan ujinya, karena semakin banyak akan membuat aplikasi web yang menggunakan AJAX dan JSON lebih baik kinerjanya. 


\section{DAFTAR PUSTAKA}

[1] Mesbah Ali and Deursen Arie Van, (2007), "A component and push-based Architectural Style for Ajax Application", Elsevier.

[2] Ying Ming, Miller James, (2012), "Refactoring legacy AJAX applications to improve the efficiency of the data exchange component", Elsevier.

[3] Zakki Abdillah, M . (2014), "Pemanfaatan Rich Internet Application (RIA) pada Sistem Informasi Akademik (SIA) menggunakan AJAX".

[4] Chasseur Craig, Li Yinan, and Patel Jignesh M, (2013), "Enabling JSON Document Stores in Relational System".

[5] Zhong Jiusheng, Jiang Nan and hu Bin.(2011). "Research and Design of $a$ Novel Webgis Framework Based on REST and RIA". Elsevier.

[6] Montoto Paula, Pan Alberto, Raposo Juan, Bellas Fernando and Javier Lopez, (2009), "Automated browsing in Ajax Website", Elsevier.

[7] Luis Canovas Izquierdo. Javier and Cabot Jordi, (2016), "JSONDISCOVERER: Visualizing the schema lurking behind JSON documents", Elsevier. 